\title{
UMA REVISÃO BIBLIOGRÁFICA QUE MOSTRA A REALIDADE DOS APENADOS NOS PRESÍDIOS BRASILEIROS E SEUS DIREITOS
}

\author{
Bruno da Silva Nascimento Soares ${ }^{1}$ \\ Gislaine Silveira Nunes ${ }^{2}$ \\ Aline Andressa Trennepohl Borges ${ }^{3}$ \\ Lucas Peixoto da Silveira ${ }^{4}$ \\ Fábio Lopes Schwertz ${ }^{5}$ \\ Carla Pilling dos Santos ${ }^{6}$
}

RESUMO: O presente trabalho propõe-se a uma sucinta análise que mostra a preocupação em torno dos direitos humanos que torna-se cada vez mais necessária devido às grandes desigualdades sociais que afetam nossa sociedade e geram consequente violação a esses direitos. É necessário que os direitos humanos sejam pensados de modo contínuo, em todos os espaços, em todos os momentos. A finalidade deste estudo é mostrar a situação do sistema prisional brasileiro e apresentar os seus principais problemas, apontando assim o princípio da dignidade da pessoa humana e seus direitos. A desestruturação do sistema prisional evidencia o descaso da prevenção e da reabilitação do preso. A importância dos direitos humanos, relata que esses se posicionam como previsões absolutamente necessárias a todas as constituições, no sentido de consagrar o respeito à dignidade humana, garantir a limitação de poder e visar ao pleno desenvolvimento da personalidade humana. Vários fatores se englobam para um precário sistema prisional. Entretanto, o abandono e o descaso do poder público ao longo dos anos vieram por agravar ainda mais a desordem do sistema prisional brasileiro. A superlotação no sistema prisional é um dos grandes problemas, impedindo que possa existir qualquer tipo de ressocialização e atendimento à população carcerária, o que faz surgir, constantes rebeliões. Destacando-se também que a alimentação é precária, sendo que a assistência médica, higiene e dentre outros elementos necessários para a vida dos apenados são insuficientes. Sabemos que o direito à saúde e a educação é um direito fundamental e social. Nosso maior desafio é consumar para que se torne possível sua concretização, de modo consciente e razoável. O cárcere atual está ignorando os direitos humanos, em especial o direito à saúde. Há negligência estatal, conforme os dados trazidos pelo presente trabalho, o cárcere é sinônimo de esquecimento e abandono.

Palavras-chave: Ressocialização. Direitos Humanos. Saúde.

\footnotetext{
${ }^{\mathrm{I}}$ Graduado em Administração pelo Centro Universitário Metodista (IPA). Pós-graduado em Gestão Prisional pela Faveni. Policial Penal da SEAPEN/RS.E-mail: Bruno.nascimento.adm@gmail.com.

${ }^{2}$ Graduada em Comunicação Social- Habilitada em Relações Públicas pela Universidade Federal do Rio Grande do Sul (UFRGS). Pós-graduada em Perfis criminais e comportamentais pela IBRA. Policial Penal da SEAPEN/RS. Email: gislainesilveirar6@gmail.com.

${ }^{3}$ Graduada em Ciências Contábeis pela Universidade de Passo Fundo(UPF). Pós-graduada em Segurança Pública pela Faculdade Alfamérica. Policial Penal da SEAPEN/RS. E-mail:aline_atb@hotmail.com.

${ }^{4}$ Graduado em Engenharia de Produção pela Faculdade Anhanguera do Rio Grande. Pós-graduado em Gestão Prisional pela faculdade Faveni. Policial penal da SEAPEN/RS. E-maillucas2246@hotmail.com

5 Graduado em licenciatura em História pela Universidade Luterana do Brasil (Ulbra). Pós-Graduado em Gestão Prisional pela Faculdade Faveni. Policial Penal da SEAPEN/RS. Email:fabio8slopes@yahoo.com

${ }^{6}$ Graduada em Educação física pelo Instituto Porto Alegre da Igreja Metodista. Centro Universitário Metodista. Policial Penal da SEAPEN/RS. E-mail:carlapillings@gmail.com.
} 
ABSTRACT: The present work proposes a succinct analysis that shows the concern around human rights that becomes increasingly necessary due to the great social inequalities that affect our society and generate consequent violations of these rights. It is necessary that human rights be considered continuously, in all spaces, at all times. The purpose of this study is to show the situation of the Brazilian prison system and present its main problems, thus pointing out the principle of human dignity and your rights. The destructuring of the prison system shows the neglect of prevention and rehabilitation of the prisoner. The importance of human rights reports that these are positioned as absolutely necessary provisions for all constitutions, in the sense of enshrining respect for human dignity, guaranteeing the limitation of power and aiming at the full development of the human personality. Several factors come together for a precarious prison system. However, the abandonment and neglect of public authorities over the years have further aggravated the disorder in the Brazilian prison system. Overcrowding in the prison system is one of the great problems, preventing any type of re-socialization and assistance to the prison population, which gives rise to constant rebellions. It is also highlighted that food is precarious, and medical care, hygiene and other elements necessary for the life of inmates are insufficient. We know that the right to health and education is a fundamental and social right. Our biggest challenge is to consummate so that its realization becomes possible, in a conscious and reasonable way. The current prison is ignoring human rights, especially the right to health. There is state negligence, according to the data brought by this work, prison is synonymous with forgetfulness and abandonment.

Keywords: Resocialization. Human rights. Health.

\section{INTRODUÇÃO}

O presente trabalho propõe-se a uma sucinta análise que mostra a preocupação em torno dos direitos humanos que torna-se cada vez mais necessária devido às grandes desigualdades sociais que afetam nossa sociedade e geram consequente violação a esses direitos. É necessário que os direitos humanos sejam pensados de modo contínuo, em todos os espaços, em todos os momentos.

A população carcerária no Brasil é uma das maiores do mundo, ultrapassando a marca de 700.000 (setecentos mil) presos, entre presos definitivos e presos provisórios, no ano de 2016. O percentual de presos provisórios dentro do sistema carcerário é de, aproximadamente, 40\%.

O declínio do sistema prisional brasileiro atinge não somente os apenados, mas também as pessoas que estão em contato com essa realidade carcerária de forma direta ou indireta. Os presídios atualmente proporcionam um ambiente degradante e desumano ao preso, tendo em vista, a superlotação, a ausência de assistência médica, a precariedade na alimentação e a falta de higiene que desencadeiam diversas doenças.

Muitos apenados acabam esquecidos nos presídios, em virtude do abandono familiar, não tendo assim, um alicerce. E como já vivem em um ambiente, no qual o tratamento é desumano e ainda sem ajuda da família, acabam estes muitas vezes se tornando pessoas piores do que já eram antes mesmo de estarem presos. 
O entendimento sobre a ressocialização do preso é de suma importância, para que seja realizada uma nova reintegração dessa pessoa na sociedade, fazendo com que cumpra as regras e se relacione novamente com todos, de forma igual e digna. Sendo isso, um direito de todos apenados que estão tentando ter uma vida de igualdades.

Mostrando que é dever do Estado em cumprir com o que está imposto na legislação brasileira para proteção e bem-estar do apenado, algo que deveria acontecer mais que na realidade é totalmente diferente, onde o governo deixa muito a desejar nesta questão. Dando ênfase aos direitos que todos os presos possuem.

Será abordada neste estudo uma revisão bibliográfica que mostra a realidade do sistema prisional brasileiro e o princípio da dignidade da pessoa humana e terá o objetivo de mostrar os direitos que o preso tem para ressocialização, voltar a ter uma vida digna e visando a esclarecer se é cumprido o papel na proteção desses frente aos estabelecimentos prisionais, com foco de mostrar também como é a saúde dos mesmos dentro do presídio.

\section{REVISÃO BIBLIOGRÁFICA}

O sistema prisional brasileiro se apresenta como um local para punição gerido pelo Estado, segregando e controlando a "classe subalterna", considerada como "classe perigosa", servido assim de desculpa para o capitalismo mascarar o problemas gerados pelo elevado, Sendo a maior força repressora do Estado contra os pobres do modo de produção capitalista (SANTOS, R; SANTOS, C. J. 2019).

O sistema penitenciário brasileiro, atualmente, tem grandes dificuldades estruturais e organizacionais, dentre elas, têm-se a superlotação nos presídios, as péssimas condições sanitárias, a má qualidade dos alimentos fornecidos, o descaso quanto à assistência médica, além da precária assistência judiciária, educacional e profissionalizante. (PACI, M. F. 2014)

É nessa sistemática que os meios de comunicação têm mostrado que, os presos, por meio de rebeliões, estão reivindicando e, ao mesmo tempo, denunciando as situações apresentadas acima, tendo como agravante de tudo isso a superlotação dos presídios. Em virtude do excesso humano nos presídios, o Estado não consegue fornecer, de modo satisfatório, os instrumentos mínimos para garantir os Direitos Humanos do preso. (BITTAR, E. C. B; ALMEIDA, G. A. 2005)

Essas atitudes violentas nos presídios e na sociedade, cujo condão é a reivindicação de melhores condições no cárcere, surgem porque, embora exista uma vasta legislação que assegura 
aos detentos os Direitos e garantias fundamentais, a realidade se mostra em confronto com todos estes direitos. De fato, as garantias e direitos fundamentais restam inertes na dogmática jurídica, enquanto as análises empíricas da situação social e jurídica dos presos mostram que, em sua grande maioria, estes indivíduos (sobre) vivem de modo desumano. (JÚNIOR, J. C. R; NÓBREGA, A. C. O. 2018)

Os estabelecimentos penais, ou unidades penais, são locais destinados ao cumprimento da pena privativa de liberdade, em regime fechado, semiaberto ou aberto, e podem abrigar, ainda, os presos provisórios que aguardam julgamento, desde que separados dos presos com condenação definitiva, nos termos do artigo 82 da LEI DE EXECUÇÃO PENAL. (NUCCI, G. S. 2014)

A importância dos direitos humanos, relata que esses se posicionam como previsões absolutamente necessárias a todas as constituições, no sentido de consagrar o respeito à dignidade humana, garantir a limitação de poder e visar ao pleno desenvolvimento da personalidade humana. Assim, observa-se que os direitos humanos não são tidos apenas como desejáveis aos cidadãos; ao contrário, configuram um direito inalienável de qualquer pessoa, em qualquer lugar do mundo. (MORAES, A. 2000).

Infelizmente sabemos que no nosso país o sistema carcerário é precário e que a Constituição resguarda sobre os direitos humanos que muitas vezes não é aplicado nas cadeias, uma vez que vemos que os indivíduos passam por humilhação, sem nenhuma dignidade humana, situações degradantes. E mais uma vez encontramos uma saída na ressocialização. (CAMPOS, A. C. A; SANTOS, E. L. 2014).

Os presídios atualmente proporcionam um ambiente degradante e desumano ao preso, tendo em vista, a superlotação, a ausência de assistência médica, a precariedade na alimentação e a falta de higiene que desencadeiam diversas doenças. (MACHADO, N. O; GUIMARÃES, I. S. 2014)

De acordo com a legislação brasileira, o cumprimento de pena restritiva de liberdade tem como objetivo à reinserção do preso à sociedade. Assim, o infrator deve ter acesso aos meios que permitam a sua reeducação, viabilizando a sua ressocialização e readaptação ao convívio social no final da sua condenação. (CHAVES, G. C, et al. 202I)

O objetivo da ressocialização é esperar do delinquente o respeito e a aceitação de tais normas com a finalidade de evitar a prática de novos delitos. (BITENCOURT, C. R. 200I)

A superlotação, a precariedade e a insalubridade das prisões resultam em um ambiente propício à proliferação de epidemias e ao contágio de doenças. Os apenados ficam expostos à 
contaminação por vários tipos de doenças, denotando a falta de cuidado com o ser humano. (WACQUANT, L. 200I)

O Estado, mesmo ciente de todas as condições subumanas a que os presos são expostos, continua negligenciando a situação do preso, tratando as prisões como um depósito de lixo humano e de seres inservíveis para o convívio em sociedade. Isso não apenas agrava a situação carcerária, como também demonstra o descaso das autoridades, com a violação do princípio garantido Constitucionalmente: os Direitos e Garantias Fundamentais. (LIMA, B. C; LIMA, M.C. 2014)

São necessárias políticas públicas para a reinserção do encarcerado na sociedade, como por exemplo, a Associação de Proteção e Assistência aos Condenados, onde os presos são chamados de reeducando, criando um reconhecimento de si mesmo, sendo responsável por sua recuperação, mesmo sob uma rígida disciplina, não há policiais ou agentes penitenciários (FALCÃO, A. L. S; CRUZ, M, V. G. 2015).

A proposta de ressocialização apontada no Direito Penal, Lei de Execução PenalLEP e Regulamento Disciplinar Prisional-REDIPRI, ao impor sofrimento, dor e humilhação ao preso, a prisão torna o preso uma pessoa sem perspectivas futuras, o faz pensar em vingança, o faz inconformado com a situação na qual é lançado: desemprego, discriminação, revolta e miséria, e, como eles mesmos dizem, a prisão os faz pessoas piores. É exatamente por não cumprir este objetivo, de tornar o preso "dócil”, fazê-lo um cidadão de bem, conformado com sua situação, é que muitos voltam a recorrer ao crime na busca de terem suas necessidades materiais e sociais satisfeitas. (OLIVEIRA, N. M, et al, 20I7).

Ainda que historicamente as prisões tenham surgido com a finalidade de punição para recuperação moral dos detentos, ratifica que este modelo não preenche as necessidades políticosociais de recuperação da população carcerária para o retorno à sociedade. Afastar o sujeito de seu ambiente sem oferecer condições de saúde, trabalho ou de construção de um novo projeto de vida tem resultado no aumento evidente da violência institucional e social, afetando diretamente os índices de reincidência na criminalidade e o consequente aumento da população carcerária. A ressocialização só será possível quando o individuo a ser ressocializado e o encarregado da ressocialização aceitem ou compartilhem o mesmo entendimento acerca da norma social vigente. (BARCINSKI, M, et al, 2017).

Para que a ressocialização seja realizada com efetividade, ela deverá ser formada por três pilares fundamentais que são: a educação, a capacitação profissional e o trabalho. Esses pilares 
possuem como meta a ampliação do grau de escolaridade do apenado, qualificando-o profissionalmente e depois, ainda dentro do estabelecimento prisional, inseri-lo no mercado de trabalho. A educação, por ser um direito de todos e obrigação do Estado, conforme descrito na CRFB/1988, é um direito fundamental para a concretização da liberdade e que será utilizada para o bem comum. Deste modo, os estabelecimentos prisionais buscam elevar a escolaridade dos apenados, pois uma parcela significativa possui baixa escolaridade ou nenhuma (ensino fundamental) e outros não possuem o ensino médio completo. $O$ apenado que frequenta as aulas, será contada da seguinte forma: a cada i6 (dezesseis) horas de aulas ministradas, diminui-se or (um) dia de sua pena. E para que isto ocorra, o governo contrata professores para darem aulas aos apenados e há também, casos de apenados que tiveram a oportunidade de sair para realizar a prova do Enem, lembrando que esta saída irá depender de sua conduta dentro do presídio. (CALMON, J. V, 2014).

Tendo em vista o apenado trabalhar, é dever e direito do mesmo, estabelecidos na Lei de Execução Penal, o trabalho é considerado, por muitos, uma verdadeira terapia - a laborterapia. Terapia porque incute no preso a vontade de sentir-se útil e produtivo, aumenta sua autoestima, propicia a inclusão e integração com a sociedade, mostrando novos caminhos fora da criminalidade. Além disso, gera renda para o preso e sua família, fortalecendo o núcleo familiar e, por consequência, promovendo o crescimento da economia local. As formas de trabalho são: Trabalho interno, que acontece dentro da unidade prisional; Trabalho externo, que ocorre extramuros, com presos do regime semiaberto, aberto e fechado. (JUNIOR, J. C. M. N, 20II).

Denota-se que a ressocialização do apenado só se torna efetiva quando de fato ocorre a integração entre sociedade e condenado, na medida em que, somente pela convivência o indivíduo sentir-se-á incluso, se afastando da marginalidade por enxergá-la como prejudicial aquele grupo do qual entende fazer parte. Dessa forma, deve ser derrubada a barreira do preconceito, com o objetivo de permitir ao preso conviver harmoniosamente com o seu próximo, após o cumprimento da pena. (RIBEIRO, J. R. F, et al, 2018).

Considera-se ressocialização o bom aproveitamento dos programas aplicados ao preso por meio da custódia, da prestação de assistência jurídica, psicossocial, à saúde, educacional, trabalhista, religiosa, bem como a garantia da visitação e do lazer. (FREITAS, G.C. 2013).

Desde o momento em que nascemos, temos direitos: saúde, moradia, educação, uma alimentação adequada, trabalho, ter uma renda suficiente, entre outros requisitos básicos para 
viver com dignidade. Eles fazem parte da nossa legislação e são inegociáveis. (BARROS, D. F; CARNEIRO, S. 20II)

\section{METODOLOGIA}

Utilizou como metodologia a revisão bibliográfica, que identifica, seleciona e avalia pesquisas consideradas relevantes.

Para a coleta de dados, foram utilizadas bases gerais na área dos direitos humanos, ressocialização e saúde utilizando as bases de dados: Google acadêmico, Scientific Electronic Library Online (Scielo), Site da Constituição da República Federativa do Brasil e Ministério da Saúde do Brasil.

Selecionaram-se pesquisas pelo título, resumo e sua pertinência ao objetivo sem restrição ao tipo de estudo, forma de apresentação e idioma.

\section{DISCUSSÃO E RESULTADOS}

A dignidade da pessoa humana compreende um valor essencial que é capaz de unificar todo o sistema normativo, assumindo o núcleo básico para critério de orientação e compreensão

do Constitucional. Nesse contexto, os direitos humanos fundamentais estão intimamente ligados com a garantia de não atuação do Estado no âmbito da vida privada individual e a tutela da dignidade da pessoa humana, com um reconhecimento universal pela maioria dos Estados, tanto na esfera constitucional, como infraconstitucional, bem como por tratados e convenções internacionais. OS direitos humanos, portanto, ultrapassam sua função originária de proteção da dignidade humana, passando a integrar conjunto de normas, embasando todo o sistema jurídico para positivar os direitos humanos. (SARLET, I. W. 2015).

Existe superlotação nas carceragens, elevado índice de reincidência; ociosidade ou inatividade forçada; condições de vida precárias; higiene precária dos presos; grande consumo de drogas; negação de acesso à assistência jurídica e de atendimento médico, dentário e psicológico aos reclusos; ambiente propício à violência física e sexual; efeitos sociológicos e psicológicos negativos, produzidos pela prisão. (BITENCOURT, C. R. 2004)

$\mathrm{O}$ autor nos mostra que um dos maiores problemas do sistema prisional brasileiro, certamente é a insalubridade e a superpopulação. A insalubridade dos presídios coloca as pessoas, que se encontram reclusas nestas instituições, em uma situação de vulnerabilidade. Elas podem 
adquirir outros agravos e doenças simplesmente por habitarem em celas geralmente sujas e superlotadas.

Pessoas privadas de liberdade são largadas dentro de um sistema precário, totalmente sem assistência do Estado e são deixadas para serem recrutadas pelo crime organizado, colocadas em celas construídas para abrigar 5 pessoas onde são colocadas 20 e devem sobreviver sem os níveis básicos de dignidade e privação de direitos.

O Brasil ocupa o $20^{\circ}$ lugar no mundo, revelando, a cada ano, aproximadamente 70 mil novos casos e 4,6 mil mortes. Esses dados permitem identificar a tuberculose como um sério problema de saúde pública no país e essa situação agrava-se quando o foco de análise passa a ser o sistema penitenciário brasileiro. (WINTER, B. C. A, GARRIDO, R. G, 2017)

Da análise do material empírico foi possível analisar ações educativas para o controle da tuberculose no ambiente prisional. É abordado problemas como, fragilidades relacionadas ao acesso e acessibilidade do doente privado de liberdade aos serviços de saúde. Destacam-se: retardo do diagnóstico; tratamento baseado na entrega ou não do medicamento; dificuldades na disposição de viaturas para levar a instituições de saúde de alto nível tecnológico e falta de informações recebidas pelos profissionais de saúde no ambiente prisional.

Em algumas pesquisas, autores também encontram esses problemas dentro da maioria dos presídios brasileiros. A saúde dos presos é um ponto preocupante desta análise histórica. Já salientamos que um dos slogans da "penitenciária modelo" era as edificações que atenderiam melhor à necessidade básica de saúde dos que lá viviam ou sobreviviam. Pois bem, reside aqui um dos pontos de maior incongruência. Uma penitenciária já antecedia o quadro deficitário da saúde dos presos que. Em um breve levantamento de ordem estatística, é notável que i2\% dos presos (em uma escala de 2.000 indivíduos) faleceram por tuberculose. $O$ fato de a doença ser respiratória acaba por agravar seus efeitos em um local onde muitos compartilham dos espaços comuns e até dos não comuns. Obviamente que, vistas as condições da época, muitos presos já traziam a doença de fora - e que era agravada lá dentro. A responsabilidade do Estado perante esta triste realidade está na ausência de um local próprio para o tratamento (D’ELIA, F. S, 20I2).

A principal razão para o alto índice de doenças contagiosas nas prisões é a superlotação e, nesse aspecto, o Brasil com uma média de três presos por vaga, tem uma das maiores taxas do mundo, perdendo apenas para China e Bulgária. Tal situação, observada em várias partes do país, constitui-se em ambiente propício à proliferação do M. tuberculosis, significando uma incidência supostamente maior do que na sociedade livre (MENEZES, R. P. O, 2002). 
No Brasil, a ocorrência de tuberculose em prisões vem sendo descrita como um alarmante problema de saúde pública em muitos países. A prevalência mundial de tuberculose entre detentos pode ser até 50 vezes maior do que as médias nacionais. Em 2012, a prevalência de tuberculose em todo mundo foi estimada em 169 casos por Ioo.00o habitantes, enquanto a prevalência média de tuberculose em presídios de diferentes regiões do mundo, entre 1993 e 20II, foi de I913 casos por roo.ooo habitantes (MINISTÉRIO DA SAÚDE, 2014).

Assim, surge a Constituição Federal para positivar os direitos humanos fundamentais que devem ser garantidos a todos os indivíduos, e por eles exercidos, bem como para limitar os poderes e abusos do próprio Estado. (NUNES, D. H, et al. 2019)

Diante dessa situação precária no sistema prisional, os autores declaram que um ambiente equilibrado pode gerar maior confiança entre os detentos, tornando mais produtivo o trabalho, fazendo assim com que o detento consiga ter uma vida com integridade dentro dos presídios e podendo voltar a conviver com a sociedade quando estiverem livres.

O problema fundamental em relação aos direitos do homem, hoje, não é tanto o de justificá-los, mas o de protegê-los. Trata-se de um problema não filosófico, mas político. (BOBBIO, N. 2004)

Os direitos humanos visam garantir que nenhum ser humano, ainda que condenado por crime grave estando preso, sofra tortura ou qualquer tratamento degradante, que cause sofrimento físico ou mental ao indivíduo. Não há que se discutir que todo ser humano, ainda que esteja preso, deve ter um tratamento digno.

É de conhecimento de todos que a superlotação não afeta somente o preso, mas sim a sociedade em geral o fato de pessoas estarem privadas de liberdade não imputa a elas que deixem de ser cidadãos, pessoas que deveriam perder somente o direito de mobilidade muitas vezes perdem sua dignidade e sofrem violências em seus direitos fundamentais casos em que não possuem acessibilidade a itens básicas devido ao sistema extremamente lotado e sem estrutura.

\section{CONCLUSÃO}

Consideramos que este estudo aborda um campo ainda pouco explorado.

O direito à saúde foi reconhecido como um direito humano e fundamental na Constituição de 1988 para todos os indivíduos, encarcerados ou não. No entanto, o cenário nas penitenciárias contrasta com a disposições legais, pois, além de faltarem estabelecimentos prisionais, os existentes e em efetiva operação estão em situação degradante e caótica. 
É importante ressaltar que em um cenário onde há aglomeração de pessoas, o confinamento determina a rápida propagação de bactérias, fazendo com que os detentos tenham vulnerabilidade a problemas de saúde.

$\mathrm{O}$ atual momento revela a necessidade dos presídios terem um ambiente salubre para que não tenha contaminações graves. Evitando que se crie surtos da doença dentro do presídio.

Isso dependeria da ação de políticas públicas para executar estratégias, como investimentos em recursos humanos e financeiros para assegurar aos milhares de brasileiros privados de liberdade o acesso à saúde. Evitando assim, que se propague esse tipo de morbidade com os detentos e evitando também mortalidade, não como privilégio ou por compaixão, mas como um direito constitucional.

Sabemos que o direito à saúde e a educação é um direito fundamental e social. Nosso maior desafio é consumar para que se torne possível sua concretização, de modo consciente e razoável. O cárcere atual está ignorando os direitos humanos, em especial o direito à saúde. Há negligência estatal, conforme os dados trazidos pelo presente trabalho, o cárcere é sinônimo de esquecimento e abandono.

\section{REFERÊNCIAS BIBLIOGRÁFICAS}

ALEX, A. A. et al. Os direitos humanos do preso e a ética. Jurisvox: Patos de Minas. n.4, p.IIII22, dez. 2002.

CHAVES, G. C; TEIXEIRA, P. T. F; MARANHÃO, T. L. G. Direitos dos Presos e Reinserção Social de Ex-presidiários pelo Trabalho: Uma Revisão Sistemática. Id on Line Rev. Psic. V.15, N. 57. Outubro, 202I.

BARCINSKI, M; CÚNICO. S. D; BRASIL, M. V. Significados da ressocialização para agentes penitenciárias em uma prisão feminina: entre o cuidado e o controle. Temas psicol. vol.25 no.3 Ribeirão Preto, 2017.

BARROS, D. F.; CARNEIRO, S. Revoluções e direitos humanos: educação, revoluções e seus direitos. São Paulo: Instituto de Tecnologia Social ITS Brasil; SESC SP, pag.88, 201 .

BITTAR, E. C. B; AlMEIDA, G. A. Curso de filosofia do direito. Atlas, 2005.

BITENCOURT, C. R. Falência da pena de prisão: causas e alternativas. 2 ed. São Paulo: Saraiva, 2001 .

BITENCOURT, C. R. Falência da pena de prisão: causas e alternativas. 3. ed. São Paulo: Saraiva, 2004.

BOBBIO, Norberto. A Era dos Direitos. 13ª reimpressão. Rio de Janeiro: Editora Elsevier, 2004. 
CALMON, J. V. ANÁLISE DO PROCESSO DE RESSOCIALIZAÇÃO, COM FOCO À REINSERÇÃO DO INDIVÍDUO NA SOCIEDADE. Disponível em: <https://monografias.brasilescola.uol.com.br/direito/anAlise-processo-ressocializacao-comfoco-a-reinsercao-individuo.htm>. Acesso em 4 de novembro de 202I.

CAMPOS, A. C. A; SANTOS, E. L. A RESSOCIALIZAÇÃO DO PRESO JUNTO À SOCIEDADE. Rev. Cien. Elet. do Curso de Direito. 6ª Edição, 2014.

FALCÃO, A. L. S.; CRUZ, M. V. G. O método APAC-Associação de Proteção e Assistência aos Condenados: Análise sob a perspectiva de alternativa penal. IV Congresso Consad. Brasília, p. I-26. 〈https://www.escoladegestao.pr.gov.br/arquivos/File/2015/VIII_Consad/30.pdf>. Acesso em 5 de novembro de 202I.

FREITAS, G. C. PROJETO DE PESQUISA APLICADA: "A RESSOCIALIZAÇÃO DO PRESO FRENTE AO SISTEMA PENITENCIÁRIO BRASILEIRO”. Disponível em: 〈http://www.escolasuperior.mppr.mp.br/arquivos/File/Projetos\%2ode\%2oPesquisa\%20Aplicad a/Gisele_Caldeira_de_Freitas.pdf $>$. Acesso em 4 de novembro de 202I.

JUNIOR, J. C. M. N. Mão de Obra Carcerária. Ministério Público do Estado de Goiás, 2oII.

JÚNIOR, J. C. R; NÓBREGA, A. C. O. OS DIREITOS POLÍTICOS DO PRESO PROVISÓRIO: UMA ANÁLISE DA (IM) POSSIBILIDADE DO VOTO. Revista de Teorias da Democracia e Direitos Políticos. Salvador, v. 4, n. I, p. 39 - 55, 2018.

LIMA, B. C; LIMA, M.C. A REALIDADE DO SISTEMA PRISIONAL BRASILEIRO: LIMITAÇÃO DOS DIREITOS FUNDAMENTAIS NOS PRESÍDIOS BRASILEIROS. Iniciação Científica CESUMAR, v. I6, n. I, p. 67-77, 2014.

MACHADO, N. O; GUIMARÃES, I. S. A Realidade do Sistema Prisional Brasileiro e o Princípio da Dignidade da Pessoa Humana. Rev Eletrônica de Iniciação Científica. Itajaí, v. 5, n.I, 2014.

MORAES, A. Direitos humanos fundamentais, teoria geral: comentários aos arts. $\mathrm{I}^{\circ}$ ao $5^{\circ}$ da Constituição da República Federativa do Brasil. 3. ed. São Paulo: Atlas, 2000.

NUCCI, G. S. Manual de Processo Penal e Execução Penal. II ${ }^{\mathrm{a}}$ edição. Rio de Janeiro: Forense, 2014 .

NUNES, D. H; LEHFELD, L. S; TOMÉ, S. C. DIREITOS HUMANOS DOS ENCARCERADOS E DIGNIDADE DA PESSOA HUMANA: Aspectos materiais vigentes. Disponível em: 〈http://www.periodicoseletronicos.ufma.br/index.php/revistahumus/article/view/Io40o〉. Acesso em 5 de novembro de 2021.

OLIVEIRA, N. M; HENRIQUE. K. S; SIQUEIRA. P. P, CLER. T; CARVALHO, M. H. SISTEMA PENAL BRASILEIRO: RESSOCIALIZAÇÃO OU REAJUSTAMENTO? II Jornada de Iniciação Científica da FACIG, 2017.

PACI, M. F. Sistema prisional brasileiro. ETIC - encontro de iniciação científica, v. 9, n. 9, 2014. 
SANTOS, R.; SANTOS, C. J. Serviço Social: uma análise crítica sobre o Sistema Prisional Brasileiro como espaço ocupacional do/a Assistente Social. Anais do i6o CBAS, Brasília, v.ı6, n.I, 2019.

SARLET. I. W. A eficácia dos Direitos Fundamentais. I2 $^{\text {a }}$ edição. Porto Alegre: Livraria do advogado, 2015.

RIBEIRO, J. R. F; BRITO, R. G. G; OLIVEIRA, T. B. A RESSOCIALIZAÇÃO DO APENADO POR MEIO DA PARTICIPAÇÃO DA SOCIEDADE: O TRABALHO COMO INSTRUMENTO NO PROCESSO DE REINTEGRAÇÃO. Ver. do Dir, vol. 5, no. I, 2018.

VARELLA, D. Estação Carandiru. São Paulo: Companhia das Letras, 1999.

WACQUANT, L. As prisões da miséria. Rio de Janeiro: Jorge Zahar, 200 . 